\title{
Farmers' Perception Analysis about the Use of Information and Communication Technologies(ICT) in Agriculture Extension services of Khyber Pakhtunkhwa
}

\author{
Abdus Salam* and Muhammad Zafarullah Khan
}

Department of Agricultural Extension Education and Communication, The University of Agriculture, Peshawar, Khyber Pakhtunkhwa, Pakistan.

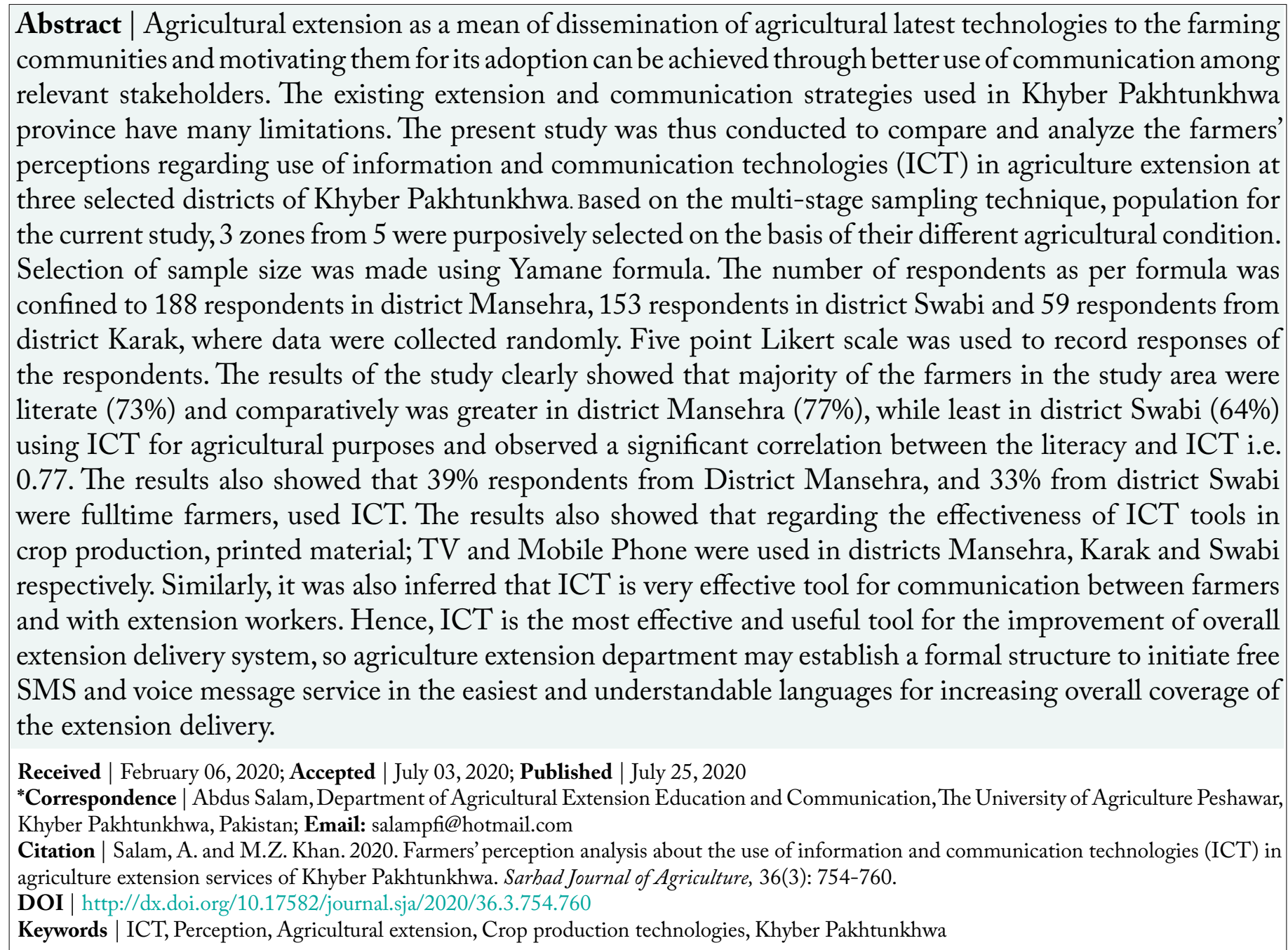

\section{Introduction}

$\mathrm{I}$ n Pakistan, greater proportions of the farming communities are un-educated, inadequately informed and socially barred about latest growth in the agriculture area (Zakar and Zakar, 2007). This is not because they are not favoring the updated innovative technologies but the truth is that 
the supportive network and the new innovative technologies were not exposed to them once in a while. The poverty level hinders them to various additional benefits of ICTs and hence destabilized the farmers' capacity to strive for the best knowledge transfer sources in agriculture. Basically, the Pakistani farmers depend on diverse helpless circumstances. They do not have access to the quality means such as transport and communication, human services, water and sanitation, training and so on. Monetarily they are vulnerable to exploitation of the middlemen to market their products. Additionally, they have low aptitude towards specialized information and skills that how to store and further process their produce towards value addition and for its onward marketing (Zakar and Zakar, 2007).

Presently well informed farmers can survive to get the ultimate benefits of their farming by choosing the appropriate agricultural inputs and a scope of other rural information sources for overall agricultural development. In addition, farmers also require updated learning for land preparation, intercropping, water application and other crop production and post-harvest technologies etc. In the quickly changing neighborhood and global agriculture market and value system, it is hard for the conventional farmers to keep up their intensity, without utilizing the propelled innovative technologies which is taken a toll proficient and guarantees high profitability. To tackle all advanced farming practices, one should be very much educated, and be systematic in his/her approach to achieve a high rate of return (Khan et al., 2016).

In order to keep the farmers informed about every innovation regarding agriculture, it is important to equip them with the latest knowledge and advanced skills of farming (Sanaullah et al., 2020). For this purpose, communication between various stakeholders in agricultural sector needs to be improved i.e. proper use of ICT could bring change in sustainable dissemination of agricultural innovation on the small and large scale. The current study is therefore focuses on to study and analyze the current status of use of ICT in various selected districts of Khyber Pakhtunkhwa for bringing more realistic picture of the use of ICT.

Objectives of the study are:

1. To assess the farmers' perceptions regarding the use of ICT in crop production technologies in the selected study area.

2. To ascertain farmers' perceptions regarding the relevance of ICT in Agricultural extension services in the selected study area.

3. To forward recommendations on the basis of overall results and conclusions drawn for its future consideration.

\section{Materials and Methods}

\section{Universe of the study}

The whole province of Khyber Pakhtunkhwa was considered as the universe of the study. The population of the study comprised the total number of farmers in the province.

\section{Selection of sample}

The current study used the multi stage sampling technique to draw the required sample size for the information collection. A sample is called a multi stage sample when it is selected in various stages, the sample units at each stage being sub-sampled from the large units selected at the previous stage. Cochran (1977) adopted the said technique in its study. For the selection of sample size, we used Yamani formula (Singh and Masuku, 2014) which is the simplified formula for proportions, $95 \%$ confidence level and $\mathrm{P}$ $=0.5$ are assumed i.e.

\section{$n=N /\left(1+N e^{2}\right) \ldots .($ Yamane formula; Yamane, 1967$)$}

\section{Where;}

$\mathrm{N}=$ total population size; $\mathrm{e}=0.05$ standard error.

\section{Data collection and information tools}

Data were collected while taken into consideration the objectives of the study. For primary data collection, a well-structured interview schedule was prepared. Different items were included regarding the multiple variables based on objectives and the nature of the respondents Five-point Likert scale was used to record responses of the respondents.

\section{Interview procedure}

The interview procedure was made easier and understandable keeping in mind that most of farmers had low education level (Sanaullah and Pervaiz, 2019). The farmers' consent was ensured to be a part of the survey. The data collection was carried accordingly after checking validity and reliability of the research instrument. 
Validity

Validity is the extent to which the interpretations of the results of a test are justified. It ensures the correctness of the research instrument according to the purpose of its use, where its credibility is established by subject experts. Before data collection, the developed instrument was checked by professionals from Agricultural Extension department, The University of Agriculture Peshawar.

\section{Reliability}

Reliability of the research instrument is the complement of the validity. Cronbach's Alpha is a well-known test to compute the constancy of interview schedule. Considering the significance of this technique, reliability was identified using SPSS v.20 where the calculated reliability value obtained was 0.78 .

\section{Data analysis}

The collected data was analyzed using Statistical Package for Social Sciences (SPSS) v. 20. Similarly, frequencies, percentages, Correlation and diagrams were also used to describe demographic characteristics of farmers. A 5-point Likert scale was used to measure the perceptions of farmers on use of ICT in Agricultural Extension and its ultimate role in agricultural crop production. Results were presented through descriptive statistical method to highlight the effectiveness of ICT gadgets used in agricultural extension.

\section{Statistical scoring over likert scale}

A 5 point Likert scale procedure was designed to quantify farmers' perceptions for usefulness/effectiveness of ICT in various agricultural extension services etc. Data from Likert scale were analyzed through calculation statistical scoring which is the Psychometrics techniques are being developed, instituted and refined in order to meet the quantification of traits like ability, perceptions, qualities and outlooks- the requirement of social sciences and educational researches.

$\begin{array}{llllll}\text { Likert } & \mathbf{1} & \mathbf{2} & \mathbf{3} & \mathbf{4} & \mathbf{5} \\ \text { scale } & \text { Very Low } & \text { Low } & \text { Medium } & \text { High } & \text { Very High }\end{array}$

For scoring/ranking on the likert scale, the number of responses for every specific scale from the respondents was multiplied to that concerned scale. For example, if the total respondents are 30 and the scale range is $1=$ very low, $2=$ low, $3=$ medium, $4=$ high and $5=$ very high and from the data 3 persons strongly disagree or their response is very low, so it will then have $3 \times 1=3,8$ persons disagree or low $(8 \times 2=16), 5$ persons somehow agree/medium $(5 \times 3=15), 9$ persons agree $(9 \times 4=36)$ and 5 persons strongly agree $(5 \times 5=25)$. Total score $=$ $3+16+15+36+25=95$.

\section{Correlation analysis}

Data on farm households' socio-economic characteristics and the overall use of ICT were associated through estimation of correlation coefficients. Correlation is a statistical technique that shows whether a variable pair is correlated and how strongly it is correlated. The main result of the correlation is called the correlation coefficient (or " $\mathrm{r}$ "). It ranges from -1.0 to +1.0 . The closer $\mathrm{R}$ is to +1 or -1 , The Closer The correlation between the two variables. If $\mathrm{r}$ is close to 0 , there is no relationship between variables. If $\mathrm{r}$ is a positive number, it means that as one variable becomes larger, the other becomes larger. If $\mathrm{r}$ is negative, it means that as one becomes larger and the other becomes smaller (often referred to as "inverse" correlation).While correlation coefficients are usually reported as $r=($ values between -1 and +1 ), squaring them makes it easier to understand. The square of the coefficient (or $r$ squared) is equal to the percentage of variables in one variable that are related to another variable.

\section{Results and Discussion}

\section{Literacy wise distribution of respondents}

Education plays an important part in human learning process and also having a strong association with the acquisition of information through media as stated by Ekanem et al. (2006). Similarly, education is also the key factor which can be helpful in managing healthy communication among the farmers and controlling authority. Previous study by Abbas et al. (2008) argued that the literate farmers can use agriculture tools better as compared to the illiterate or uneducated agriculturist.

The Figure 1 shows the findings of literacy wise distribution of the sample farmers taken from the three districts. The findings show that majority of the farmers (73\%) were literate, while a better number (27 percent) of the respondents were illiterate as far as the three districts were concerned. The district wise distribution of the data shows that 36 percent respondents in Mansehra district, 25 
percent from District Swabi and 11 percent from District Karak were literate. The finding indicates that the education is having positive relationship with the study objectives. The education from the perspective of use of ICT tools has significant role in performing different agriculture activities. The educated farmer can easily understand the needs and importance of ICT gadgets in the agriculture activities and different extension services. The findings are consistent with the study of Okwu et al. (2007).

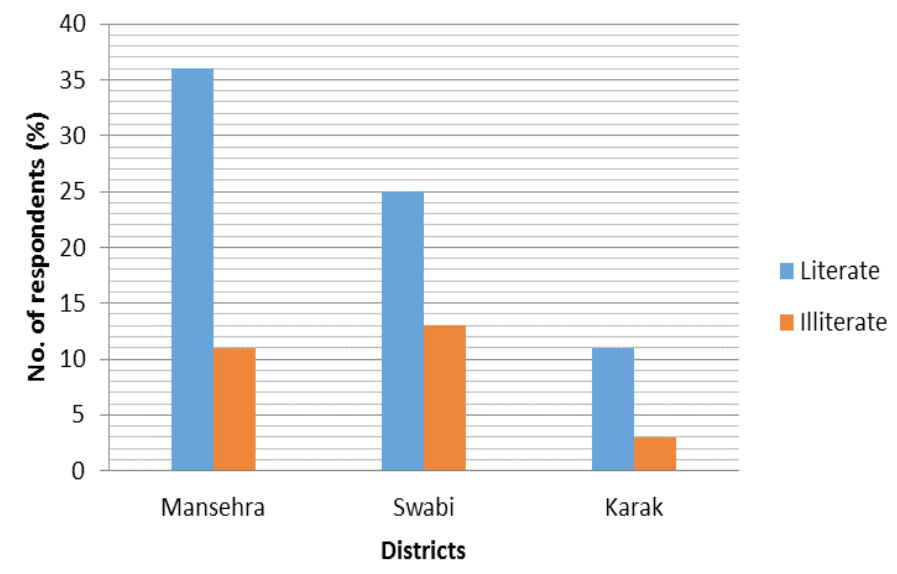

Figure 1: Distribution of respondents regarding literacy status.
Involvement in farming

The farmers involvement in the farming is the important activity which can be viewed their interest and evaluation in the different agriculture practices. The study of Abdullah et al. (2005) argued that the farmers who have adopted farming as full time are more inclined in adopting those techniques which can be used in the development of agriculture and for availing extension services. The collected data were presented in Figure 2 accordingly. The values show that 39\% respondents from District Mansehra, and 33\% from district Swabi were full time farmers. However, in Karak District majority of the farmers i.e. $10 \%$ were as part time farmers. The values also suggested that majority of the respondents (77 percent) in the whole study area were full time farmers, while a limited numbers i.e. $23 \%$ were part time farmers. The findings are supported by Sanaullah et al. (2020) where full time involvement in agriculture was found having highly significant effect on crop yield. Farmers gain more experience in full time farming due to which they become more flexible towards the acceptance of updated information as stated by Agwu et al. (2008) that experience has a due importance in the adoption of agricultural technologies.

Table 1: Ranking of various ICTTools as per their use and effectiveness in to disseminate information's regarding crop production technologies.

\section{District Mansehra}

District Karak

$\begin{array}{lllllllll}\text { Rank } & \text { Tool } & \text { Score } & \text { Rank } & \text { Tool } & \text { Score } & \text { Rank } & \text { Tool } & \text { Score } \\ 1 & \text { Printed material } & 766 & 1 & \text { TV } & 249 & 1 & \text { Mobile phone } & 568 \\ 2 & \text { Radio } & 752 & 2 & \text { Radio } & 171 & 2 & \text { Computer } & 310 \\ 3 & \text { TV } & 495 & 3 & \text { Printed material } & 170 & 3 & \text { Radio } & 326 \\ 4 & \text { Computer via internet } & 420 & 4 & \text { Computer via internet } & 158 & 4 & \text { TV } & 320\end{array}$
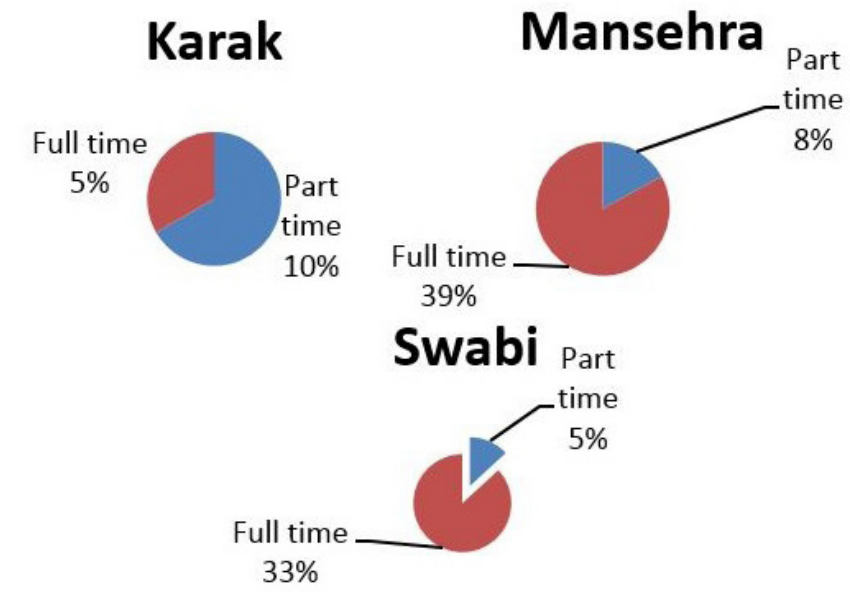

Figure 2: Distribution of respondents regarding farming involvement.
Distribution of respondents regarding crop production technologies

The department is conducting training sessions to educate the farmers about the crop production and protection technologies through ICT. Crop production practices is always one of the main needs of the farmers to train them in the latest technologies of how to grow a healthy crop and to improve their produce and in this regard the department of agriculture extension in the selected districts was always there to build the capabilities of farming communities to take a good produce of their crops. Table 1 shows the results of crop production services offered by the extension office, in District Mansehra, 
the Printed with 766 score was mostly used to help the farmers in benefitting the technologies of crop production in an efficient manner. Radio with 752 score was at $2^{\text {nd }}$ rank and TV with 495 score was found at $3^{\text {rd }}$ place. In District Karak, TV with 249 score was ranked on the top, radio with 171 score was at $2^{\text {nd }}$ rank and Printed material with 170 score was found at $3^{\text {rd }}$ place. Similarly, in Swabi District, mobile phone was mainly used to give advices to the farmers and get feedback with 568 score, computer via internet with 510 score was at $2^{\text {nd }}$ rank and radio with 329 score was at $3^{\text {rd }}$ place.

Table 2: Distribution of respondents regarding their perception for the relevance of ICT tools in extension services in the District of Mansehra, KP-Pakistan.

\section{Farmers perceptions}

\section{Rank Item}

1 Make extension service delivery more cost Score effective

2 Best source of learning

3 Contacts between farmers and extension work- 677 ers

4 Best source of information sharing between 656 farmers

$5 \quad$ Can be usefull for enhancing overall agricultural 598 productivity

$6 \quad$ Very useful for adoption and diffusion of latest 573 agricultural technologies

7 Creating awareness among farmers 551

8 Increase collaboration between extension and 442 input supplier agencies

9 Intra contacts between extension workers 364

10 Incorporate feed-forward and improve feedback 305 mechanism

11 Can lead to global cross sharing of ideas between farmers and extension workers (677 score). Least number of respondents were agreed that it can play its role for global cross sharing of ideas (290 score).

Table 3: Distribution of respondents regarding their perception for the relevance of ICT tools in extension services in the District of Karak, KP-Pakistan.

\section{Farmers' perceptions}

Rank Item

1 Contacts between farmers and extension work- 249 ers

2 Best source of information sharing between farmers

3 Best source of learning

4 Can be useful for enhancing overall agricultural 195 productivity

$5 \quad$ Very useful for adoption and diffusion of latest 193 agricultural technologies

6 Intra contacts between extension workers 163

$7 \quad$ Creating awareness among farmers 161

$8 \quad$ Can lead to global cross sharing of ideas 147

9 Incorporate feed-forward and improve feedback 137 mechanism

10 Increase collaboration between extension and 131 input supplier agencies

11 Will make extension service delivery more cost 125 - effective

Table 4: Distribution of respondents regarding their perception for the relevance of ICT tools in extension services in the District of Swabi, KP-Pakistan.

\section{Farmers perceptions}

\section{Rank Item}

Intra contacts between extension workers

Can be useful for enhancing overall agricultural 701 productivity

3 Contacts between farmers and extension work- 681 ers

$4 \quad$ Increase collaboration between extension and input supplier agencies

$5 \quad$ Very useful for adoption and diffusion of latest 573 agricultural technologies

districts, farmer's perceptions were recorded and presented in Tables 2, 3 and 4 respectively.

\section{District Mansehra}

The majority of the scores for District Mansehra illustrate that ICT can make the extension services most cost effective (725 score), $2^{\text {nd }}$ rank suggested that the use of ICT tool is the best source of learning (686 score). Similarly, most of the farmers were also agreed that use of ICT can be very effective for contact
Best source of learning

7 Creating awareness among farmers

8 Will make extension service delivery more cost 420 - effective

9 Best source of information sharing between farmers

10 Incorporate feed-forward and improve feedback 320 mechanism

11 Can lead to global cross sharing of ideas 
Table 5: Distribution of respondent's regarding correlation of ICT and literacy status.

$\begin{array}{llll}\text { Education status } & \text { ICT } & \text { Literate } & \text { Illiterate } \\ \text { ICT } & 1 & & \\ \text { Literate } & 0.771^{* *} & 1 & \\ \text { Illiterate } & 0.027^{\mathrm{NS}} & .112 & 1 \\ \text { * indicate significant at 1percentlevel of significance; NS shows non } \\ \text { significant. }\end{array}$

Table 6: Distribution of respondent's regarding correlation of ICT and farming status.

$\begin{array}{llll}\text { Status } & \text { ICT } & \text { Part time } & \text { Full time } \\ \text { ICT } & 1 & & \\ \text { Part time } & .112^{\mathrm{NS}} & 1 & \\ \text { Full Time } & .642^{* *} & .137 & 1 \\ \text { ** indicate significant at 1percentlevel of significance; NS shorws non } \\ \text { significant. }\end{array}$

\section{District Karak}

Table 3 shows the findings of farmer's perceptions for the relevance of ICT tool in the agriculture extension in District Karak. The majority of the scores show that ICT tool can make the process of contact between the extension workers and farmers very effective (249 score), $2^{\text {nd }}$ rank suggested that the use of ICT tool is the best source of information's sharing between farmers (239 score), the $3^{\text {rd }}$ rank shows that these methods was the best source of learning (217 score) (Table 3). Similarly, its use for enhancing the overall agricultural productivity at $4^{\text {th }}$ rank and its use for adoption and diffusion process was also opted. Least respondents were agreed that it can be used to make the extension service delivery more cost-effective.

\section{District Sruabi}

Table 4 shows that use of ICT can make the extension services more cost effective (790 score), $2^{\text {nd }}$ rank suggests that the use of ICT tool is the best source of learning (701 score), the $3^{\text {rd }}$ rank shows that this methods was the best source for the interaction between the extension workers and farmers (681 score) and $4^{\text {th }}$ rank shows that it was the tool which can share the information among the stakeholders. Least farmers were agreed that it can be used to lead global cross sharing of ideas.

\section{Correlation analysis}

Tables 5 and 6 show the correlations of ICT and literacy status of the respondents. The results show a positive and significant $(\mathrm{P}<0.01)$ correlation between the literate $(0.771)$ respondents and ICT. Correlations of farming status with ICT were determined by using bivariate correlation analysis and the results are presented in Table 4. It is evident from the results that the coefficient of correlation of the respondents lying in the category of full time farming is high (0.642) suggesting that there is a positive and significant $(\mathrm{P}<0.01)$ correlation between the ICT and full time farming.

\section{Conclusions and Recommendations}

From the findings of the above study, it is very much clear that incorporation and use of ICT as an information source in Khyber Pakhtunkhwa scenario showed a very trend change (present to future) from radio towards TV and other ICT gadgets like android mobile phones, internet etc. Majority of the farmers in the study area believed that using of mobile phones and Internet facilities etc. can be a cheaper and quickest source of media for sharing of information. Despite of various advancements and the facilities and infrastructure available in terms of ICT and its use as a source of information in agriculture sector, Khyber Pakhtunkhwa scenario, the results are very discouraging as compared to its use on national and international level. The farmers are still using the old source of ICT like radio and printed material as a major source of information, however, the farmers were hoping the incorporation and provision of a formal structure in terms of mobile phone technologies, Internet, advanced radio and TV facilities, the innovations in the field of agriculture can be improved towards overall improved agricultural productivity. The overall views of respondents on the future use of ICT in agricultural extension services were very encouraging. Improvements in the future over the current situation indicate that there will be greater access to information and communication technologies if major technological barriers are removed.

Since the Radio appeared as major ICT gadgets for sharing of very useful information in agriculture, hence there is a dire need for the strengthening and up-gradation of this important medium in Agriculture Extension. It is recommended that the existence structure of the Radio may be rived and separate FM radio channel exclusive for agriculture and livestock sectors may be set up at several sites of the province. As Android Mobile phone is a very useful and multi- 
purpose tool as far as to bring innovation in the future dissemination of information for Agriculture Extension in Khyber Pakhtunkhwa is concerned, the Agriculture Extension department may establish a formal structure to initiate free SMS and voice message service in the easiest and understandable languages. These services should also be focused on providing market information, weather updates etc.

The farmers believed that use of ICT in the field of agriculture as an information source is very much necessary for getting maximum crop production. The farmers can be motivated and trained for using the various ICT gadgets through various technical and skilled training programs by the concerned Farm Services Centers (FSC) or District Extension offices if provided the access to free helpline available on mobile phone.

\section{Novelty Statement}

This research study is unique in the sense that such type of comprehensive work has not been conducted in Khyber Pakhtunkhwa regarding farmers' perception on use of modern technologies in agriculture. This endeavor could have a significant contribution in encouraging farming community regarding use of ICT.

\section{Author's Contribution}

Abdus Salam designed the research work, collected and analyzed the data and wrote first draft of the paper. Muhammad Zafarullah Khan developed the main theme of the study and supervised the whole process of research work.

\section{Conflict of interest}

The authors have declared no conflict of interest.

\section{References}

Abbas, M., T.E. Lodhi, A. Bashir and M. Ather. 2008. Dissemination of wheat production technologies and interface of out-reach efforts with farmers. J. Agric. Res. 46(1). http://www. jar.com.pk/displayprods.asp.

Abdullah, A., W.A. Gillani, S. Naveed, K. Amanullah and H. Kashif. 2005. Computerized farm guide: Using ICT for better dissemination of agriculture extension information. Center Agro-Inf. Res. Natl. Univ. Comput. Emerg. Sci. Islamabad, Pakistan.

Agwu, A.E., J.N. Ekwueme and A.C. Anyanwu. 2008. Adoption of improved agricultural technologies disseminated via radio farmer program by farmers in Enugu State, Nigeria. Afr. J. Biotechnol. 7(9): 1277-1286. https://doi. org/10.4314/as.v7i2.1594

Cochran, W.G., 1977. Sampling Techniques, Third Edition, New York: John Wiley and Sons.

Ekanem, E., M. Mafuyai-Ekanem, F. Tegegne, S. Muhammad and S. Singh, 2006. Consumer trust in extension as a source of biotech food information. J. Ext., 44(1). http://www.joe.org/ joe/2006february/rb2.php

Khan, Ali., A.Jaffar, R. Qamar, F. Shagufta, A. Nida, R. Arsalan, A. Zulfiqar and M. Basharat. 2016. Overview of ICT in agricultural development of Baluchistan Province of Pakistan. Int. J. Adv. Res. Biol. Sci., 3(7): 16.

Okwu, O.J., A.A. Kuku and J.I. Aba, 2007. An assessment of use of radio in agricultural information dissemination: A case study of radio Benue in Nigeria. Afr. J. Agri. Res., 2(1): 014-018. http://www.academic journals.org/ AJAR

Sanaullah, U. Pervaiz, S. Ali, M. Fayaz and A. Khan. 2020. The impact of improved farming practices on maize yield in Federally Administered Tribal Areas, Pakistan. Sarhad J. Agric. 36(1): 34-43. https://doi.org/10.17582/journal. sja/2020/36.1.348.358

Sanaullah and U. Pervaiz. 2019. An effectiveness of extension trainings on boosting agriculture in federally administered tribal areas (FATA) of Pakistan: An evidence from Bajaur agency. Sarhad J. Agric., 35(3): 890-895. https://doi. org/10.17582/journal.sja/2019/35.3.890.895

Singh, A. and M.B. Masuku. 2014. Sampling techniques and determination of sample size in applied statistics research: An overview. Int. J. Eco. Commerce Mgt. Vol. II, pp. 15.

Yamane, T., 1967. Statistics, An introductory analysis, $2^{\text {nd }}$ ed., New York: Harper and Row.

Zakar, M.Z and R. Zakar. 2007. Diffusion of information technologies for agricultural dev. in rural Punjab: Challenges and opportunities, Islamabad, Pakistan. 